\title{
A Retrospective Study on the Efficacy of a Ten- Milligram Dosage of Atorvastatin for Treatment of Hypercholesterolemia in Type 2 Diabetes Mellitus Patients
}

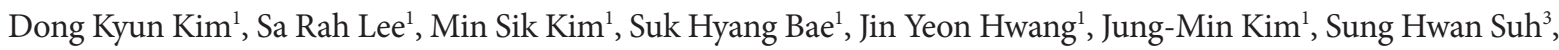 \\ Hye-Jeong Lee ${ }^{2}$, Mi Kyoung Park ${ }^{1}$, Duk Kyu Kim ${ }^{1}$ \\ Departments of ${ }^{1}$ Internal Medicine and ${ }^{2}$ Pharmacology, Dong-A University Medical Center, Dong-A University College of Medicine, Busan, \\ ${ }^{3}$ Department of Internal Medicine, Samsung Medical Center, Sungkyunkwan University School of Medicine, Seoul, Korea
}

\begin{abstract}
Background: There have been few clinical studies on $10 \mathrm{mg}$ atorvastatin as a starting dosage for treatment of hypercholesterolemia in type 2 diabetes mellitus (T2DM) patients. This retrospective study aims to evaluate the efficacy of $10 \mathrm{mg}$ dosage of atorvastatin in clinical setting.

Methods: One hundred five enrolled patients with high levels of low density lipoprotein cholesterol (LDL-C, $>100 \mathrm{mg} / \mathrm{dL}$ ) took $10 \mathrm{mg}$ atorvastatin. After 6 months, they were divided into 'Responder group' (LDL-C $<100 \mathrm{mg} / \mathrm{dL}$ ) and 'Non-responder group' (LDL-C $\geq 100 \mathrm{mg} / \mathrm{dL}$ ), and the response rate was calculated. Thereafter, we subdivided the 'Responder group' into Maintenance (10 mg), Reduced dosage (5 mg), and Discontinuance group ( $0 \mathrm{mg}$ ). The 'Non-Responder group' was subdivided into Maintenance $(10 \mathrm{mg})$ and Double dosage group $(20 \mathrm{mg})$. After consecutive 6 months, the response rates of each $10 \mathrm{mg}$ Maintenance groups were compared to those of the other groups, respectively.

Results: Following the first 6 months, the response rate of $10 \mathrm{mg}$ fixed dosage was $74.3 \%$. In the 'Responder group', response rates of $10 \mathrm{mg}, 5 \mathrm{mg}$ and Discontinuance groups following 6 months were $52.6 \%, 53.1 \%$, and $12.5 \%$, respectively. In the 'Non-responder group', response rates of $10 \mathrm{mg}$ and $20 \mathrm{mg}$ groups were $28.6 \%$ and $50.0 \%$. Baseline LDL-C levels and body mass index (BMI) of 'Responder group' were significantly lower than those of 'Non-responder group' ( $P=0.004$, respectively).

Conclusion: Hypercholesterolemia treatment with $10 \mathrm{mg}$, fixed dosage of atorvastatin was effective in three quarters of the subjects during the first 6-month treatment; however, a significant number of patients with high LDL-C levels and/or BMI require higher starting and maintenance dosage.
\end{abstract}

Keywords: Atorvastatin; Diabetes mellitus, type 2; Hypercholesterolemia

\section{INTRODUCTION}

Cardiovascular disease is the leading cause of death in type 2 diabetes mellitus (T2DM) patients [1,2], and the primary cause of cardiovascular disease is atherosclerosis. Hypercholesterol- emia, in turn, is a major risk factor for atherosclerosis [3].

Hypercholesterolemia is also an important risk factor of diabetic retinopathy and nephropathy. Therefore, management of hypercholesterolemia is important in the treatment and prevention of vascular complications in diabetic patients [4-6].
Corresponding author: Duk Kyu Kim

Department of Internal Medicine, Dong-A University College of Medicine,

Dongdaesin-dong, Seo-gu, Busan 602-714, Korea

E-mail: dkkim@dau.ac.kr

Received: Jun. 20, 2010; Accepted: Sep. 17, 2010
This is an Open Access article distributed under the terms of the Creative Commons Attribution Non-Commercial License (http://creativecommons.org/licenses/by-nc/3.0/) which permits unrestricted non-commercial use, distribution, and reproduction in any medium, provided the original work is properly cited. 
According to the National Cholesterol Education Program Adult Treatment Panel (NECP ATP) III guidelines proposed in 2001, control of low density lipoprotein cholesterol (LDLC) levels is considered to be the most important aim for prevention of diabetic complications such as cardiovascular disease. Because T2DM is considered a cardiovascular disease (CVD) risk equivalent, it is recommended that LDL-C levels remain below $100 \mathrm{mg} / \mathrm{dL}$ in diabetic patients with hypercholesterolemia [7].

The guidelines were revised in 2004 to propose maintaining LDL-C levels below $70 \mathrm{mg} / \mathrm{dL}$ in patients at very high risk for diabetic complications [8]. Updated therapeutic guidelines from the Korean Society of Lipidology and Atherosclerosis (KSLA) proposed similar recommendations. In addition, therapeutic recommendations are similar between the Korean Diabetes Association (KDA) and American Diabetes Association (ADA) $[4,5,9]$.

Although previous studies and guidelines from NCEP, ADA, and KDA have suggested overall recommendation for prescribing lipid lowering agents, or therapeutic goals, there is a lack of information on the practical use of lipid lowering agents, such as recommendations for starting dosage and dosage adjustment.

In practice, a typical statin therapy starting and maintenance dosage of atorvastatin is $10 \mathrm{mg}$ per day [10,11]. It is generally accepted that the therapeutic dosage for statins in the Asian population is lower than in Caucasians for control of hypercholesterolemia $[12,13]$. Thus, we hypothesized that $10 \mathrm{mg}$ atorvastatin dosage may be adequate as a starting and maintenance dosage for control of hypercholesterolemia in T2DM patients.

To verify our hypothesis, we evaluated the response rate of a $10 \mathrm{mg}$ atorvastatin fixed dosage after 6 months of treatment.

Additionally, we wanted to know how to adjust the dosage when the target LDL-C levels were achieved, or not, by statin therapy. Thus, we compared the response rate of $10 \mathrm{mg}$ atorvastatin treatment to the response rates for differently adjusted dosages, all following 6 months of treatment.

\section{METHODS}

\section{Subjects}

We evaluated the medical records of 415 T2DM patients who were registered at the Diabetic Center of Dong-A University Medical Center (DCDAMC) and had been prescribed atorvastatin for treatment of hypercholesterolemia from January 2001 to June 2008.

Inclusion criteria for the subjects were: 1) T2DM patients with hypercholesterolemia (LDL-C $>100 \mathrm{mg} / \mathrm{dL}$ ) who were managed following the lipid-lowering protocol proposed by the DCDAMC, and 2) patients should not have used any lipidlowering agents during the 2 months prior to enrollment in the study.

Patients with type 1 diabetes mellitus (T1DM), baseline LDL-C levels above $250 \mathrm{mg} / \mathrm{dL}$, primary hyperlipoproteinemia, thyroid disease, chronic liver disease such as liver cirrhosis, malignancy, chronic kidney disease and secondary DM with potential effects on their glucose and lipid metabolism, were excluded. T2DM patients who had developed coronary artery disease after 2004 also were excluded.

Among the original 415 T2DM patients, 105 (49 males and 56 females) met the inclusion and exclusion criteria and were enrolled in the study.

\section{Methods}

This is a retrospective study to evaluate the efficacy of a $10 \mathrm{mg}$ fixed dosage of atorvastatin for treatment of hypercholesterolemia in T2DM patients.

All of the enrolled patients were managed according to the lipid-lowering protocol of the DCDAMC.

Atorvastatin protocol set forth by the DCDAMC for treatment of hypercholesterolemia with T2DM is as follows:

1) Use atorvastatin $10 \mathrm{mg}$ as a starting dosage and maintain same dosage for a maximum of 6 months.

2) Check fasting lipid profiles every 2 or 3 months during the 6-month therapy period.

3) Responders with LDL-C levels below $100 \mathrm{mg} / \mathrm{dL}$ have three options for further management, at the discretion of their physician: A) stop taking atorvastatin, B) reduce dosage to $5 \mathrm{mg}$, or $\mathrm{C}$ ) maintain the $10 \mathrm{mg}$ dosage.

4) Non-responders with LDL-C levels above $100 \mathrm{mg} / \mathrm{dL}$ have two options for further management, also at the discretion of the physician: A) maintain a $10 \mathrm{mg}$ dosage, or B) increase dosage to $20 \mathrm{mg}$.

All the subjects were divided into 'Responder' and 'Non-responder' after initial 6 months of therapy as the protocol.

To evaluate the efficacy of the 6-month $10 \mathrm{mg}$ atorvastatin treatment, we calculated the response rate, which was defined as the number of responders divided by the number of enrolled patients.

Subjects were divided into Responder and Non-responder 
groups following the initial 6-month therapy period, and underwent an additional 6 months of treatment per the options set forth in the protocol. Following the second 6 month therapy period, the 'Responder group' was divided into two subgroups, a Remission maintenance group and a Remission maintenance failure group, according to plasma levels of LDLC (Fig. 1). Remission was defined as final LDL-C levels maintained below $100 \mathrm{mg} / \mathrm{dL}$. We then examined the response rates for each subgroup.

The 'Non-responder group' was also further divided into two subgroups: a Delayed remission group and Remission failure group (Fig. 1). We then calculated the response rate for each subgroup.

To evaluate the long-term efficacy of the $10 \mathrm{mg}$ atorvastatin dosage, we examined response rates in a 5 year follow-up.

We hypothesized that the response rate would be different according to baseline LDL-C levels and body mass index (BMI). Thus, we stratified the patients by baseline LDL-C levels and $\mathrm{BMI}$ and compared the response rate for each group following the initial 6-month therapy period.

We collected clinical and laboratory data (DM duration, baseline LDL-C, HbA1c, and C-peptide levels, smoking history, hypertension, gender, body weight, height and baseline BMI) from the medical records and compared the data between Responder and Non-responder groups. We compared the clinical characteristics between the Remission maintenance group and the Remission maintenance failure group. We also com- pared the clinical characteristics between the Remission maintenance group of 'Responder group' and Remission failure group of 'Non-responder group'.

We selected plasma LDL-C levels as a parameter to assess the efficacy of atorvastatin treatment. Data on baseline and follow-up LDL-C levels were collected from medical records. LDL-C levels were checked every 2 to 3 months according to DCDAMC protocol.

\section{Statistical analysis}

Results of our statistical analyses are expressed as the mean and standard deviation, or as percentage, and were calculated using the statistical software package SPSS version 17.0 for Windows (SPSS Inc., Chicago, IL, USA). Baseline demographics and clinical characteristics were analyzed using mean by frequency analysis, compare means with independent samples $t$-test. Cross tabulation analysis was used to evaluate patients response to atorvastatin and progression profiles. We examined the relationship between LDL-C levels and BMI by correlation analysis. Statistical significance was established as a $P$ value less than 0.05 .

\section{RESULTS}

\section{Baseline demographics and clinical characteristics of the study subjects}

Among the 105 enrolled patients, there were 49 men (46.7\%)

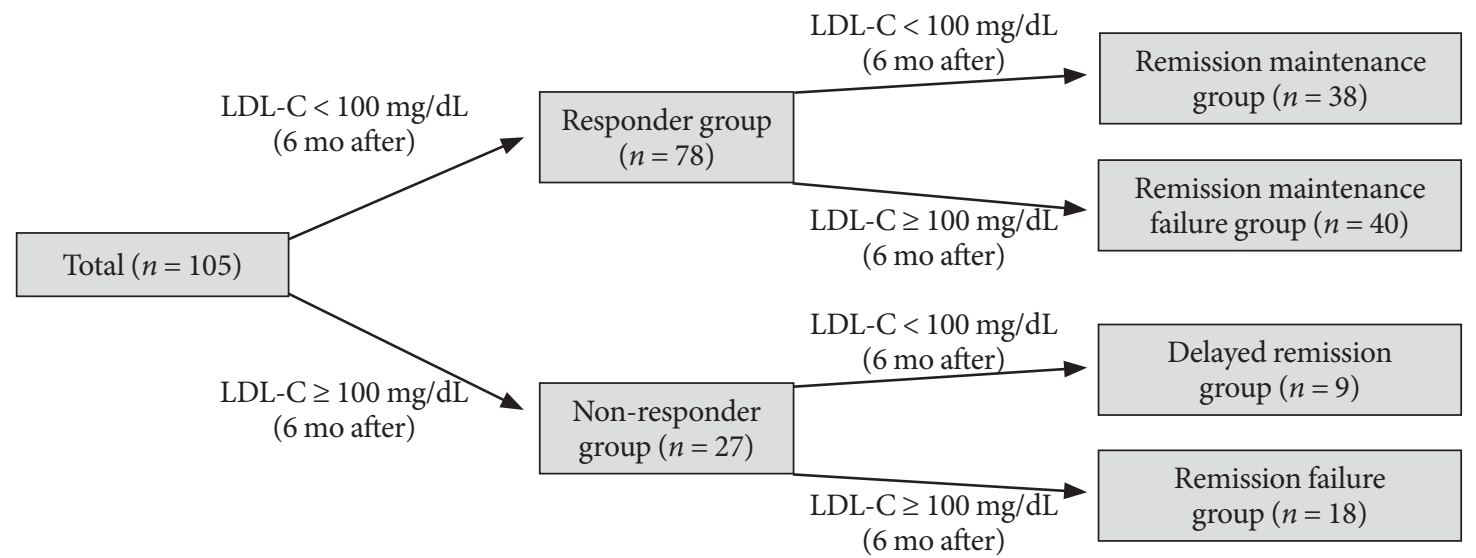

Fig. 1. Schematic flow diagram of study setting: 105 patients with type 2 diabetes mellitus (T2DM) underwent atorvastatin 10 $\mathrm{mg}$ therapy as starting dose for reducing high low density lipoprotein cholesterol (LDL-C) levels (>100 mg/dL) were enrolled for the study. After 6 months of treatment, the subjects were divided into a responder group (LDL-C $<100 \mathrm{mg} / \mathrm{dL}$ ) or Non-Responder group (LDL-C $\geq 100 \mathrm{mg} / \mathrm{dL}$ ). Thereafter, the Responder group was subdivided into a Remission maintenance group and Remission maintenance failure group. The Non-responder group was subdivided into a Delayed remission group and Remission failure group. Dosage modifications were made following a response to each dosage of atorvastatin. 
Table 1. Demographics and clinical characteristics of the study subjects

\begin{tabular}{lcc}
\hline \multirow{2}{*}{ Characteristic } & \multicolumn{2}{c}{ Total $(n=105)$} \\
\cline { 2 - 3 } & Mean $\pm \mathrm{SD}$ & Range \\
\hline Age, $\mathrm{yr}$ & $54 \pm 8$ & $20-70$ \\
DM duration, yr & $6 \pm 5$ & $0-21$ \\
Baseline LDL-C, mg/dL & $151 \pm 21$ & $111-224$ \\
HbA1c, \% & $8.0 \pm 1.4$ & $5.9-12.3$ \\
Insulin, $\mu \mathrm{IU} / \mathrm{mL}$ & $6.98 \pm 6.06$ & $0.04-35.40$ \\
C-peptide, $\mathrm{ng} / \mathrm{mL}$ & $2.11 \pm 1.12$ & $0.05-5.42$ \\
Weight, $\mathrm{kg}$ & $65 \pm 10$ & $47-103$ \\
Height, $\mathrm{m}$ & $1.62 \pm 0.07$ & $1.46-1.81$ \\
Body mass index, $\mathrm{kg} / \mathrm{m}^{2}$ & $24.9 \pm 2.8$ & $19.5-36.5$ \\
\hline
\end{tabular}

SD, standard deviation; DM, diabetes mellitus; LDL-C, low density lipoprotein cholesterol.

and 56 women $(53.3 \%)$.

The mean subject age was $54 \pm 8$ years, mean DM duration was $6 \pm 5$ years, mean baseline LDL-C level was $151 \pm 21 \mathrm{mg} /$ $\mathrm{dL}$, mean HbA1c level was $8.0 \pm 1.4 \%$, and mean BMI was $24.9 \pm 2.8$ (Table 1$)$.

Forty-three patients (41.0\%) had hypertension and 20 patients (19.0\%) had a history of smoking (data not shown).

\section{Response rate following initial 6-month therapy period with $10 \mathrm{mg}$ atorvastatin}

Among the 105 patients, 78 patients had plasma LDL-C levels below $100 \mathrm{mg} / \mathrm{dL}$ following 6 months of therapy and were placed in the 'Responder group. Thus, the response rate was $74.3 \%$. Twenty-seven patients were placed in the 'Non-responder group'.

\section{Comparison of baseline demographics and clinical characteristics of the Responder and Non-responder group following the initial 6-month therapy period}

Among several parameters that were evaluated, only baseline LDL-C levels and BMI were significantly lower in the 'Responder group' than in the 'Non-responder group' $(P=0.004$, respectively). Unexpectedly, age, DM duration, and baseline HbA1c levels were not statistically significant factors (Table 2).

Although, the proportion of hypertensive patients was lower in the 'Responder group' ( $n=29,37.2 \%)$ than in the 'Nonresponder group' ( $n=14,59.9 \%)$, there was no statistical significance between them. The proportion of patients with a smoking history was similar in the 'Responder group' $(n=15$,
Table 2. Demographics and clinical characteristics of responder and non-responder groups following 6 months of therapy

\begin{tabular}{lccc}
\hline & \multicolumn{3}{c}{ Total $(n=105)$} \\
\cline { 2 - 4 } Characteristic & $\begin{array}{c}\text { Responder } \\
(n=78,74.3 \%)\end{array}$ & $\begin{array}{c}\text { Non- } \\
\text { responder } \\
(n=27,25.7 \%)\end{array}$ & $P$ value \\
\hline Age, yr & $54 \pm 9$ & $54 \pm 7$ & 0.947 \\
DM duration, yr & $6 \pm 5$ & $7 \pm 5$ & 0.302 \\
Baseline LDL-C, $\mathbf{~ m g / d L ~}$ & $\mathbf{1 4 6} \pm \mathbf{1 7}$ & $\mathbf{1 6 3} \pm \mathbf{2 7}$ & $\mathbf{0 . 0 0 4}$ \\
HbAlc, \% & $8.2 \pm 1.5$ & $7.7 \pm 1.2$ & 0.151 \\
Insulin, $\mu \mathrm{IU} / \mathrm{mL}$ & $6.77 \pm 6.07$ & $7.58 \pm 6.10$ & 0.553 \\
C-peptide, ng/mL & $2.17 \pm 1.15$ & $1.91 \pm 1.01$ & 0.263 \\
Weight, $\mathrm{kg}$ & $65 \pm 10$ & $67 \pm 9$ & 0.231 \\
Height, $\mathrm{m}$ & $1.62 \pm 0.07$ & $1.60 \pm 0.08$ & 0.148 \\
Body mass index, $\mathbf{~ k g / \mathbf { m } ^ { 2 }}$ & $\mathbf{2 4 . 5} \pm \mathbf{2 . 7}$ & $\mathbf{2 6 . 2} \pm \mathbf{2 . 5}$ & $\mathbf{0 . 0 0 4}$ \\
\hline
\end{tabular}

Values are presented as mean \pm standard deviation.

DM, diabetes mellitus; LDL-C, low density lipoprotein cholesterol.

$19.2 \%)$ and 'Non-responder group' ( $n=5,18.5 \%)$; however, this was also shown to be statistically insignificant.

\section{Response rates in the 'Responder group' for the 3 dosage adjustment regimens following the additional 6-month therapy period}

Dosages were adjusted according to the response measured following the initial 6 months of therapy, and LDL-C levels were again measured following an additional 6 months of therapy.

In the second 6-month therapy period, the 'Responder group' was either administered a $10 \mathrm{mg}$ maintenance dosage (10 mg group), a half dosage atorvastatin ( $5 \mathrm{mg}$ group), or medication was discontinued (Discontinuance group), as per DCDAMC protocol. The response rates, based on the reference LDL-C level of $100 \mathrm{mg} / \mathrm{dL}$, were $52.6 \%$ in the $10 \mathrm{mg}$ group ( $n=20$ of 38 ), $53.1 \%$ in the $5 \mathrm{mg}$ group ( $n=17$ of 32 ), and $12.5 \%$ in the Discontinuance group $(n=1$ of 8$)$ (Table 3$)$.

\section{Response rates in the 'Non-responder group' for the 2} dosage adjustment regimens following the additional 6 months of therapy

The 'Non-responder group' received either a $10 \mathrm{mg}$ maintenance dosage (10 $\mathrm{mg}$ group) or double dosage (20 mg group) for 6 months following the initial 6-month therapy period, per DCDAMC protocol. The response rates were $28.6 \%$ in the 
Table 3. Responses following 12 months of therapy

\begin{tabular}{|c|c|c|c|c|c|}
\hline \multirow{6}{*}{$\begin{array}{l}\text { Responder } \\
(n=78)\end{array}$} & \multirow[b]{2}{*}{ Dosage after 6 mo } & \multicolumn{3}{|c|}{ Response after $12 \mathrm{mo}$} & \multirow[b]{2}{*}{$P$ value } \\
\hline & & $\begin{array}{c}\text { Remission } \\
\text { maintenance group }\end{array}$ & $\begin{array}{l}\text { Remission maintenance } \\
\text { failure group }\end{array}$ & $\begin{array}{c}\text { Remission } \\
\text { maintenance rate (\%) }\end{array}$ & \\
\hline & Stop $(n=8)$ & 1 & 7 & 12.5 & \multirow{4}{*}{0.096} \\
\hline & $5 \mathrm{mg}(n=32)$ & 17 & 15 & 53.1 & \\
\hline & $10 \mathrm{mg}(n=38)$ & 20 & 18 & 52.6 & \\
\hline & Total & 38 & 40 & 48.7 & \\
\hline \multirow{5}{*}{$\begin{array}{l}\text { Non- } \\
\text { responder } \\
(n=27)\end{array}$} & \multirow{2}{*}{ Dosage after 6 mo } & \multicolumn{3}{|c|}{ Response after $12 \mathrm{mo}$} & \multirow{2}{*}{$P$ value } \\
\hline & & Delayed remission group & Remission failure group & Delayed remission rate (\%) & \\
\hline & $10 \mathrm{mg}(n=21)$ & 6 & 15 & 28.6 & \multirow{3}{*}{0.326} \\
\hline & $20 \mathrm{mg}(n=6)$ & 3 & 3 & 50 & \\
\hline & Total & 9 & 18 & 33.3 & \\
\hline
\end{tabular}

SD, standard deviation; DM, diabetes mellitus; LDL-C, low density lipoprotein cholesterol.

Table 4. Clinical characteristics of remission maintenance group and remission maintenance failure group in responder group following 12 months of therapy

\begin{tabular}{lccc}
\hline & \multicolumn{3}{c}{ Total $(n=78)$} \\
\cline { 2 - 4 } Characteristic & $\begin{array}{c}\text { Remission } \\
\text { maintenance } \\
\text { group } \\
(n=38)\end{array}$ & $\begin{array}{c}\text { Remission } \\
\text { maintenance } \\
\text { failure group } \\
(n=40)\end{array}$ & $P$ value \\
\hline Age, yr & $55 \pm 8$ & $53 \pm 9$ & 0.274 \\
DM duration, yr & $6 \pm 5$ & $6 \pm 5$ & 0.851 \\
Baseline LDL-C, mg/dL & $143 \pm 17$ & $150 \pm 17$ & 0.087 \\
HbAlc, \% & $8.3 \pm 1.6$ & $8.0 \pm 1.4$ & 0.313 \\
Insulin, $\mu \mathrm{IU} / \mathrm{mL}$ & $6.20 \pm 6.62$ & $7.32 \pm 5.52$ & 0.421 \\
C-peptide, $\mathrm{ng} / \mathrm{mL}$ & $2.21 \pm 1.25$ & $2.13 \pm 1.07$ & 0.779 \\
Weight, $\mathrm{kg}$ & $63 \pm 8$ & $66 \pm 11$ & 0.214 \\
Height, $\mathrm{m}$ & $1.62 \pm 0.07$ & $1.62 \pm 0.07$ & 0.867 \\
Body mass index, kg/m ${ }^{2}$ & $23.9 \pm 2.2$ & $25.0 \pm 3.2$ & 0.098 \\
\hline
\end{tabular}

Values are presented as mean \pm standard deviation.

$\mathrm{DM}$, diabetes mellitus; LDL-C, low density lipoprotein cholesterol.

Maintenance dosage ( $n=6$ of 21 ) and $50.0 \%$ in the Double dosage group ( $n=3$ of 6 ) (Table 3 ).

\section{Comparison of baseline demographics and clinical characteristics of each subgroup following the additional 6 months of therapy}

We compared clinical characteristics between the Remission maintenance group and Remission maintenance failure group and found no significant differences between the two groups (Table 4).
Table 5. Clinical characteristics of Remission maintenance group in Responder group and Remission failure group in Non-responder following 12 months of therapy

\begin{tabular}{lccc}
\hline & \multicolumn{3}{c}{ Total $(n=56)$} \\
\cline { 2 - 4 } Characteristic & $\begin{array}{c}\text { Remission } \\
\text { maintenance } \\
\text { group }(n=38)\end{array}$ & $\begin{array}{c}\text { Remission } \\
\text { failure group } \\
(n=18)\end{array}$ & $P$ value \\
\hline Age, yr & $55 \pm 8$ & $54 \pm 7$ & 0.698 \\
DM duration, yr & $6 \pm 5$ & $6 \pm 4$ & 0.723 \\
Baseline LDL-C, $\mathbf{~ g / d L ~}$ & $\mathbf{1 4 3} \pm \mathbf{1 7}$ & $\mathbf{1 6 1} \pm \mathbf{2 7}$ & $\mathbf{0 . 0 1 6}$ \\
\hline HbA1c, \% & $8.3 \pm 1.6$ & $7.8 \pm 1.3$ & 0.227 \\
Insulin, $\mu \mathrm{IU} / \mathrm{mL}$ & $6.20 \pm 6.62$ & $8.23 \pm 6.50$ & 0.287 \\
\hline C-peptide, ng/mL & $2.21 \pm 1.25$ & $2.11 \pm 1.13$ & 0.765 \\
Weight, $\mathrm{kg}$ & $63 \pm 8$ & $68 \pm 9$ & 0.059 \\
Height, $\mathrm{m}$ & $1.62 \pm 0.07$ & $1.61 \pm 0.08$ & 0.440 \\
Body mass index, $\mathbf{~ k g / m ~}{ }^{2}$ & $\mathbf{2 3 . 9} \pm \mathbf{2 . 2}$ & $\mathbf{2 6 . 1} \pm \mathbf{2 . 6}$ & $\mathbf{0 . 0 0 1}$ \\
\hline
\end{tabular}

Values are presented as mean \pm standard deviation.

DM, diabetes mellitus; LDL-C, low density lipoprotein cholesterol.

We also compared clinical characteristics between the Remission maintenance group and Remission failure group. We found that in the Remission maintenance group, LDL-C levels and BMI were lower than those of the Remission failure group, with significance (Table 5).

\section{Response rates in the long-term follow-up: 5 years after initial therapy period}

Among all enrolled patients, the 5-year long term follow-up was conducted on 28 patients. Some changes in dosage had 


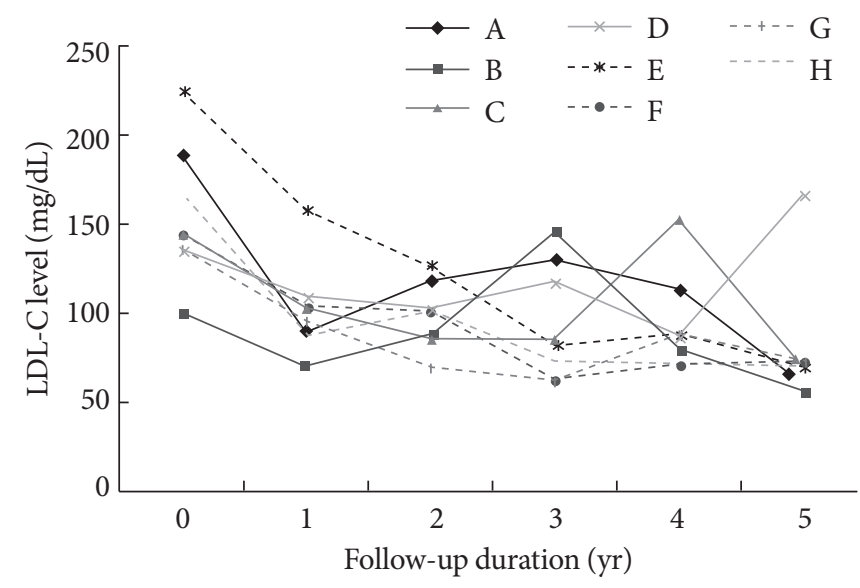

Fig. 2. Low density lipoprotein cholesterol (LDL-C) profiles during the 5 years following initial therapy with atorvastatin $10 \mathrm{mg}$. Among 28 patients, 8 patients $(\mathrm{A}-\mathrm{H})$ used atorvastatin $10 \mathrm{mg}$ as a starting and maintenance dosage without any change in dosage for the entire 5 year period. Of those 8 patients, 7 had final LDL-C levels below $100 \mathrm{mg} / \mathrm{dL}$. Therefore, for this group, the 5 -year response rate to an atorvastatin 10 mg fixed dosage was $87.5 \%$.

occurred in 20 of the patients; however, all 28 patients were administered $10 \mathrm{mg}$ atorvastatin during the 3 months immediately preceding the 5-year follow-up evaluation.

Of the 28 patients, 20 patients had LDL-C levels below 100 $\mathrm{mg} / \mathrm{dL}$, yielding an overall response rate of $71.4 \%$.

In addition, among these 28 patients, 8 patients had been administered $10 \mathrm{mg}$ atorvastatin as a starting and maintenance dosage without any change in dosage for the entire 5 years. Seven of those patients had final LDL-C levels below 100 $\mathrm{mg} / \mathrm{dL}$; therefore, the 5 -year response rate in that group was 87.5\% (Fig. 2).

\section{Correlation between statistically significant risk factors}

Baseline LDL-C levels and baseline BMI were the risk factors which influenced the response rate following 6 months of therapy. There was significant correlation between these two risk factors, and the correlation coefficient was $0.251(P=0.01)$ (Fig. 3).

\section{Six-month therapy response by baseline LDL-C levels and BMI}

As the significant risk factors among the baseline clinical characteristics were baseline LDL-C levels and BMI, we classified the subjects into 3 subgroups according to baseline LDL-C level $(<130 \mathrm{mg} / \mathrm{dL}, 130-160 \mathrm{mg} / \mathrm{dL}$, and $\geq 160 \mathrm{mg} / \mathrm{dL})$. Re-

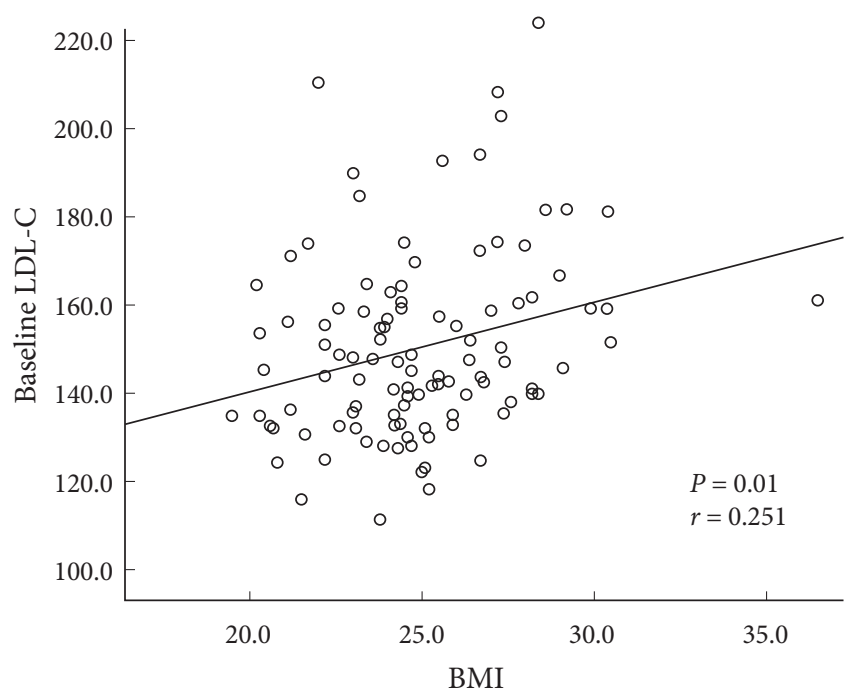

Fig. 3. Correlation between baseline low density lipoprotein cholesterol (LDL-C) levels and body mass index (BMI) (two significant risk factors for short-term non-response).There was significant correlation between these two risk factors. The correlation coefficient was $0.251(P=0.01)$.

Table 6. Response rate according to stratification by baseline LDL-C level following 6 months of therapy

\begin{tabular}{lccc}
\hline $\begin{array}{l}\text { Baseline LDL-C level, } \\
\mathrm{mg} / \mathrm{dL}\end{array}$ & $\begin{array}{c}\text { Responder } \\
\text { group } \\
(n=78)\end{array}$ & $\begin{array}{c}\text { Non- } \\
\text { responder } \\
\text { group } \\
(n=27)\end{array}$ & $\begin{array}{c}\text { Response } \\
\text { rate (\%) }\end{array}$ \\
\hline$<130(n=12)$ & 12 & 0 & 100 \\
130 to $160(n=66)$ & 48 & 18 & 72.7 \\
$\geq 160(n=27)$ & 18 & 9 & 66.7 \\
\hline
\end{tabular}

LDL-C, low density lipoprotein cholesterol.

sponse rates following the initial 6-month therapy period were $100 \%, 72.7 \%$, and $66.7 \%$, respectively (Table 6).

In addition, we also classified the enrolled patients by their WHO BMI classification category. They were divided into 4 categories: baseline BMI $\left(\mathrm{kg} / \mathrm{m}^{2}\right)<18.5$ (underweight), $18.5 \leq$ baseline BMI $\left(\mathrm{kg} / \mathrm{m}^{2}\right)<25$ (normal), $25 \leq$ baseline BMI (kg/ $\left.\mathrm{m}^{2}\right)<30$ (overweight), and baseline BMI $\left(\mathrm{kg} / \mathrm{m}^{2}\right) \geq 30$ (obese). None of the patients had a baseline BMI below 18.5. Following the initial 6-month therapy period, the responses rates for these groups were $86.4 \%, 59.5 \%$, and $50 \%$ for the normal, overweight, and obese groups, respectively (Table 7).

\section{DISCUSSION}

In this study, we found that the response rate to an initial 
Table 7. Response rate according to stratification by BMI and WHO classification following 6 months of therapy

\begin{tabular}{lccc}
\hline BMI, $\mathrm{kg} / \mathrm{m}^{2}$ & $\begin{array}{c}\text { Responder } \\
\text { group } \\
(n=78)\end{array}$ & $\begin{array}{c}\text { Non- } \\
\text { responder } \\
\text { group } \\
(n=27)\end{array}$ & $\begin{array}{c}\text { Response } \\
\text { rate }(\%)\end{array}$ \\
\hline 18.5 to $24.9(n=59)$ & 51 & 8 & 86.4 \\
25 to $29.9(n=42)$ & 25 & 17 & 59.5 \\
$\geq 30(n=4)$ & 2 & 2 & 50.0
\end{tabular}

No patients had a baseline BMI below 18.5.

BMI, body mass index; WHO, World Health Organization.

6-month therapy period with atorvastatin $10 \mathrm{mg}$ was $74.3 \%$. This result is very similar to the $75.5 \%$ response rate report by Pola et al. [14], but higher than the $59 \%$ reported by AguilarSalinas et al. [11]. Aguilar-Salinas' study, inclusion criteria of enrolled patients was an LDL-C level above $130 \mathrm{mg} / \mathrm{dL}$, which was higher than that of our study (above $100 \mathrm{mg} / \mathrm{dL}$ ).

We found that baseline LDL-C levels and BMI were significantly lower in the 'Responder group' than in the 'Non-responder group', following the initial 6-month therapy period. This result on LDL-C levels is supported by other reports [15]. Patients with high BMI showed a poor response to the usual dosage of atorvastatin. We demonstrated a significant correlation between baseline LDL-C level and baseline BMI; however, the correlation was not strong. If a poor response in patients with high BMI is independent of LDL-C level, the explanation might be simple: a greater fat mass may require a greater amount of statin. However, this explanation need to be further studied and clarified.

The clinical implication of our result is clear: patients with high LDL-C levels and/or high BMI should start treatment with a higher initial dosage of atorvastatin.

Among our subjects were patients with moderate to severe hypercholesterolemia. From the view point of current consensus for statin treatment, this group of patients was not indicated for $10 \mathrm{mg}$ atorvastatin treatment. If this group of patients had been excluded from this study, nearly all patients would have shown good response rate.

Nevertheless, the wide range of subjects and results of this study are meaningful, as this group of patients represents the typical range of patients who we meet every day in our clinic. Our results suggest that three quarters of the patients whom we care for will be responsive to $10 \mathrm{mg}$ fixed atorvastatin dosage and will reach target LDL-C goals. The quarter of patients with high baseline LDL-C levels and/or high BMI need a high- er dosage of atorvastatin. If we had excluded the group of patients with moderate to severe hypercholesterolemia from our study, we would not have found the results nearly as useful for our practice.

Guidelines for conditioning therapy in the long term following successful control of LDL-C with lipid-lowering agents have yet to be established and maintaining the same dosage of medication is the customary practice.

We compared the response rates between the Half-dosage group and Discontinuance group following the additional 6 months of therapy. The response rate was $53.1 \%$ in the Halfdosage group, which is similar to reports by others [15]. Even though the response rate of the Half-dosage group is better than that of the Discontinuance group, we do not recommend these kinds of dosage adjustments.

It was unexpected that, in the 'Responder group', LDL-C levels increased again to above $100 \mathrm{mg} / \mathrm{dL}$ in $47.4 \%$ of the 10 mg Maintenance group.

There may be several possible causes for this high rate of maintenance failure. First, the subjects may not have regularly taken their medication. Second, lifestyle modifications may not have been maintained successfully. Third, there may be a secondary failure of atorvastatin.

Dosage up-titration is a common practice with non-responsive patients. We compared the response rates of the $10 \mathrm{mg}$ Maintenance group and $20 \mathrm{mg}$ Double dosage group. The response rate of Double dosage group (50.0\%) was better than that of the Maintenance group (28.6\%).

We infer that it is necessary to increase the dosage of atorvastatin by at least double for the 'Non-responder group'. Moreover, if patients do not show a response to a $20 \mathrm{mg}$ dosage, they may need to increase to the maximal dosage of atorvastatin monotherapy $[7,8]$, and a prompt up-titration should also be applied $[11,16]$.

If patients continue to show failure of lipid control with the higher dosage of atorvastatin or experience significant side effects, we should consider adding other lipid lowering agents, such as ezetimibe [17-19].

Under these conditions, it may be worthwhile to investigate whether the patients had primary dyslipidemia or not; however, we did not perform this evaluation.

The 5-year follow-up data from this study are promising. Even though the number of patients in our study was too small to draw a certain conclusions, in does appear that long-term use of atorvastatin has a favorable lipid-lowering effect. The 
5 -year LDL-C profiles of the 8 cases who took a $10 \mathrm{mg}$ fixed dosage of atorvastatin during the entire period give us the insight that final LDL-C levels within the target range are achievable long-term, even though some fluctuations in LDL-C levels were noted during that period. The fluctuations in LDL-C levels seem to be related to compliance of the individual patient rather than the efficacy or dosage of medication (Fig. 2). We could exclude other possibilities such as the effect of concomitantly using medications or episodes of other diseases.

The results of our study are comparable to those of the Steno-2 study, although that study was on total cholesterol, not LDL-C. Nonetheless, the Steno- 2 study also showed that about $80 \%$ of subjects were controlled. In that study, however, the lipid lowering therapy was more intensive and applied for a longer period than in our study. The lipid lowering agent in the Steno-2 study was also atorvastatin, with a maximum dosage of $80 \mathrm{mg}$ daily, or the equivalent, and the study duration was 7.8 years [20].

If our results are reliable, we could hypothesize that longterm therapy with atorvastatin for diabetic patients can bring more favorable results in the control of LDL-C levels, even though prompt up-titrations were not applied. This is not the same concept as the legacy effect or metabolic memory. We hypothesized that long-term statin use decreases the size of the LDL-C pool, induces a decrease in serum LDL-C, and helps to maintain stable lipid levels.

This study has some limitations. First, the number of patients that followed the DCDAMC lipid lowering protocol was insufficient for us to enroll enough subjects, and this may add bias to our study. Second, we could not confirm that the prescribed lifestyle modifications associated with diet or exercise were performed. This may also have an effect on our results. Third, medical compliance by the enrolled patients was not guaranteed. Finally, medication history from other clinics within at least 2 months prior to study initiation was not fully identified, which may have resulted in under-estimation of the baseline or final LDL-C levels.

In conclusion, routine $10 \mathrm{mg}$ fixed dosage atorvastatin therapy is effective in about three quarters of T2DM subjects for treatment of hypercholesterolemia, during the first 6 months of therapy.

However, patients with high baseline LDL-C levels and high BMI may need a higher starting and maintenance dosage or even other therapeutic regimens, for better control.

\section{ACKNOWLEDGMENT}

This work was supported by the Dong-A University research fund.

\section{REFERENCES}

1. Stamler J, Vaccaro O, Neaton JD, Wentworth D. Diabetes, other risk factors, and 12-yr cardiovascular mortality for men screened in the Multiple Risk Factor Intervention Trial. Diabetes Care 1993;16:434-44.

2. Ho JE, Paultre F, Mosca L. Is diabetes mellitus a cardiovascular diseases risk equivalent for fatal stroke in women? Data from the Women's Pooling Project. Stroke 2003;34:2812-6.

3. Jeong YJ, Ko SK, Park HS, Yang BM. Meta-analysis and economic evaluation for the effect of statins. J Korean Soc Lipidol Atheroscler 2004;14:120-30.

4. American Diabetes Association. Position Statement. Management of dyslipidemia in adults with diabetes. Diabetes Care 2002;25(suppl 1):S74-7.

5. American Diabetes Association. Position Statement. Management of dyslipidemia in adults with diabetes. Diabetes Care 2001;24(suppl 1):S58-61.

6. Shepherd J, Cobbe SM, Ford I, Isles CG, Lorimer AR, MacFarlane PW, McKillop JH, Packard CJ. Prevention of coronary heart disease with pravastatin in men with hypercholesterolemia. West of Scotland Coronary Prevention Study Group. N Engl J Med 1995;333:1301-7.

7. Expert Panel on Detection, Evaluation, and Treatment of High Blood Cholesterol in Adults. Executive Summary of the Third Report of the National Cholesterol Education Program (NCEP) Expert Panel on Detection, Evaluation, and Treatment of High Blood Cholesterol in Adult Treatment Panel(ATP) III. JAMA 2001;285:2486-97.

8. Grundy SM, Cleeman JI, Merz CN, Brewer HB Jr, Clark LT, Hunninghake DB, Pasternak RC, Smith SC Jr, Stone NJ; National Heart, Lung, and Blood Institute; American College of Cardiology Foundation; American Heart Association. Implications of recent clinical trials for the National Cholesterol Education Program Adult Treatment Panel III guidelines. Circulation 2004;110:227-39.

9. National Cholesterol Education Program. Second report of the Expert Panel on Detection, Evaluation, and Treatment of High Blood Cholesterol in Adults (Adult Treatment Panel II). Circulation 1994;89:1333-445. 
10. Choi DS, Kim DK, Kim DM, Kim SY, Nam MS, Park YS, Shon HS, Ahn CW, Lee KW, Lee KU, Lee MK, Chung CH, Cha BY, and 83 investigators. Efficacy evaluation of atorvastatin in Korean hyperlipidemic patients with type 2 diabetes mellitus. J Korean Diabetes Assoc 2006;30:292-302.

11. Aguilar-Salinas CA, Gomez-Perez FJ, Posadas-Romero C, Vazquez-Chavez C, Meaney E, Gulias-Herrero A, Guillen LE, Alvarado Vega A, Mendoza Perez E, Eduardo Romero-Nava L, Angelica Gomez-Diaz R, Salinas-Orozco S, Moguel R, Novoa G. Efficacy and safety of atorvastatin in hyperlipidemic, type 2 diabetic patients. A 34-week, multicenter, open-label study. Atherosclerosis 2000;152:489-96.

12. Liao JK. Safety and efficacy of statins in Asians. Am J Cardiol 2007;99:410-4.

13. Lee E, Ryan S, Birmingham B, Zalikowski J, March R, Ambrose H, Moore R, Lee C, Chen Y, Schneck D. Rosuvastatin pharmacokinetics and pharmacogenetics in white and Asian subjects residing in the same environment. Clin Pharmacol Ther 2005; 78:330-41.

14. Pola P, Kumar R, Reddy AP, Rajagopal G, Harinarayan CV, Suresh V, Suchitra MM, Sachan A. Efficacy of low dose atorvastatin in diabetic dyslipidemia. J Indian Med Assoc 2009; 107:807-9.
15. Cho SW, Lee WR, Lee SY, Namkung J, Do JH. How does atorvastatin $5 \mathrm{mg}$, simvastatin $10 \mathrm{mg}$ as maintenance therapy meet the therapeutic goal of NCEP ATP III? Korean J Med 2005;69 (suppl 1):S117.

16. Atorvastatin Study Group in Korea. Flexible initial dosing of atorvastatin based upon initial low-density lipoprotein cholesterol levels in type 2 diabetic patients. Korean J Intern Med 2008;23:22-9.

17. Bae JW, Kim HS, Lee SC, Han KH, Jeon ES. The safety and efficacy of ezetimibe and simvastatin combination therapy in Koreans patients with primary hypercholesterolemia. Korean J Med 2005;68:487-97.

18. Yi MY, Bae JW, Hwang KK, Kim DW, Cho MC. The effect of dual inhibition of cholesterol in hyperlipidemia patients with acute myocardial infarction. Korean J Med 2008;74:59-67.

19. Villa J, Prately RE. Ezetimibe/simvastatin or atorvastatin for the treatment of hypercholesterolemia in patients with the metabolic syndrome, the VYMET study. Curr Diab Rep 2010; 10:173-5

20. Gaede P, Vedel P, Larsen N, Jensen GV, Parving HH, Pedersen O. Multifactorial intervention and cardiovascular disease in patients with type 2 diabetes. N Engl J Med 2003;348:383-93. 